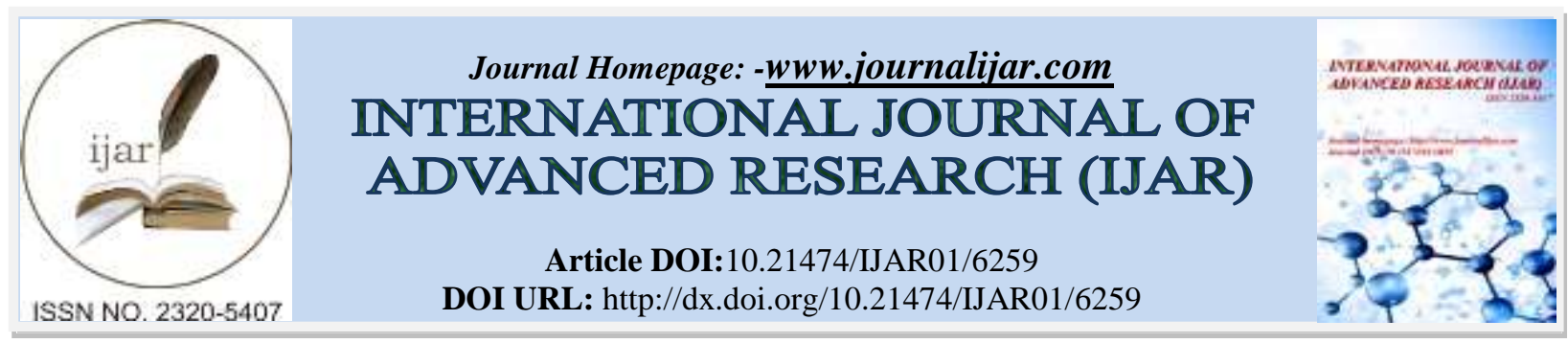

RESEARCH ARTICLE

\title{
PRELOADING VERSUS COLOADING OF CRYSTALLOID FLUID TO CONTROL HYPOTENSION DUE TO SPINAL ANESTHESIA.
}

Raad Ghazi Reshan.

High Institute for Infertility Diagnosis and ART's, Al-NahrainUniversity, Baghdad-IRAQ.

\section{Manuscript Info}

Manuscript History

Received: 09 November 2017

Final Accepted: 11 December 2017

Published: January 2018

Key words:-

Caesarean section, spinal anesthesia, preloading ,co-loading.

\section{Abstract}

Background: The choice of anesthesia for caesarean section depends upon indication for operation, its urgency, patients and obstetrician preferences and skills of the anesthetist .Either of the general and spinal anesthesia is not ideal for caesarean section because each has advantages and risk to both mother and fetus. However the aim of the anesthetist is to choose the method which is safest and most comfortable for the mother, least depressant to the newborn and which provides optimal working conditions for the obstetrician.Objectives: to clarify the effect of volume preload or co-load is better in management of the change in blood pressure after parturition under spinal anesthesia for caesarean section.

Materials and Methods: The study was carried out at Al-Sadr Teaching Hospital in Missan from January 2016 to January 2018. It was performed as comparative study on 60 healthy full term patients presented for elective lower segment caesarean section. They were divided into groups first one as thirty patients which were given crystalloid solution as preloading 15 minutes before induction. Second group as thirty patients which were given crystalloid solution as co-loading while induction of spinal anesthesia. Results: Out of 30 patients who administered preloading dose of crystalloid solution before induction of spinal anesthesia 23 patients were developed hypotension after spinal anesthesia. On the other hand out of 30 patients who administered co-loading of crystalloid solution with induction of spinal anesthesia 15 patients were developed hypotension. It had been found that those patients who were administered preloading were more likely to develop hypotension than those administered coloading. Conclusions: There is significant difference between the effect of preloading and coloading on blood pressure after spinal anesthesia.

Copy Right, IJAR, 2018,. All rights reserved.

\section{Introduction:-}

Hypotension during spinal anesthesia for cesarean delivery is a common and troublesome complication, both from the maternal and fetal-neonatal point of view. Commonly used methods for the prevention of hypotension, for example, leg wrapping, antithromboembolic stockings, patient positioning, and fluid and vasopressor administration have met with mixed success. Traditionally, crystalloid IV fluids are administered in the 20 minutes before the 
induction of spinal anesthesia for cesarean delivery (preload). The literature suggests that this is relatively ineffective since preload is rapidly redistributed[1-3]. Also, this method may induce atrial natriuretic peptide (ANP) secretion, resulting in peripheral vasodilatation followed by an increased rate of excretion of the preloaded fluid[2]. The risk of hypotension is increased in a parturient due to the higher level of block $\left(\mathrm{T}_{4}\right)$ required for the cesarean section, unique physiologic and anatomic changes of pregnancy and increased susceptibility to the effects of sympathectomy due to reduced sensitivity to the endogenous vasoconstrictors coupled with increased synthesis of endothelium-derived vasodilators[4].A more rational approach is to administer the fluid bolus at the time that the local anesthetic block is starting to take effect. This might maximize intravascular volume expansion during vasodilatation from the sympathetic blockade and limit fluid redistribution and excretion. This practice has been termed "coload"[5].

Preload augmentation of blood volume, regardless of the type of fluid, should be substantial enough to result in a significant increase in cardiac output (CO), to prevent hypotension[6].Maternal arterial blood pressure (BP) has always been used as a surrogate index of CO. However, because of changes in peripheral resistance, changes in maternal BP do not necessarily reflect changes in maternal CO[7]. Significant correlation among decreases in maternal CO after spinal anesthesia, increased umbilical artery pulsatility index and umbilical arterial acidemia at delivery suggest that changes in these variables are better predictors of reduced uteroplacental perfusion than changes in maternal BP[8]. This is further supported by placental scintigraphy which showed no correlation between maternal BP and placental blood flow[9].

\section{Material and Methods:-}

Prior to initiation of spinal block, carefully wash your hands. The patient should be attached to standard monitors including ECG, blood pressure, and pulse oximetry. Record an initial set of vital signs. Preload the patient with 0.5 1.0 liter of crystalloid intravenous solution.

The study was carried out at Al-Sadr Teaching Hospital in Missan from January 2016 to January 2018. It was performed as comparative study on 60 healthy full term patients presented for elective lower segment caesarean section. First group of thirty patients which were given crystalloid solution as preloading 15 minutes before induction. Second group of thirty patients which were given crystalloid solution as co-loading while induction of spinal anesthesia. Total 60 patients within two groups were included and a written consent was taken from each patient. History was taken from all patients in the suite which include age, parousty, duration of the pregnancy and any complicating maternal health history, anesthesia related obstetric history, blood pressure measurement, and airway assessment. History was taken from all patients in the suite, All women managed with intravenous fluids (usually lactated Ringers), blood was prepared for all patients, and patient was placed in supine position with wedge under right hip for left uterine displacement monitoring was done for the pulse, non invasive blood pressure amplifier(N.I.B.P.), oxygen saturation. During study it always were chosen the smallest cutting spinal needle size(25-27), which is preferable to decrease the incidence of post puncture headache due to leaking of cerebrospinal fluid (CSF).

Inclusion Criteria: Patients were selected from age range 18 to 37 years, with full term live single pregnancy.

Exclusion Criteria: The following patients were excluded:

1. Premature pregnancy $<37$ weeks of gestation.

2. Liver, kidney or heart failure associated with pregnancy.

3. Uncontrolled metabolic disorders (Diabetes Mellitus, Hypertension, Thyrotoxicosis ).

4. Multiple fetus pregnancy.

\section{Results:-}

Out of 30 patients who administered preloading dose of crystalloid solution before induction of spinal anesthesia 23 patients were developed hypotension after spinal anesthesia.On the other hand out of 30 patients who administered coloading of crystalloid solution with induction of spinal anesthesia 15 patient develop hypotension.

It had been found that those patients who were administered preloading dose more likely to develop hypotension than those administered coloading one.

So Chi-square test show significant relationship between hypotension and administered preloading dose of 
crystalloid solution and these results were illustrated in the table (1), and figure (1).

Table 1:-Distribution of hypotension according to Preloading/Coloading Dose.

\begin{tabular}{|c|c|c|c|c|c|}
\hline $\begin{array}{l}\text { Blood Pressure } \\
\text { Parameter }\end{array}$ & $\begin{array}{l}\text { Preloading } \\
\text { Dose }\end{array}$ & $\begin{array}{l}\text { Coloading } \\
\text { Dose }\end{array}$ & Total No. & $\begin{array}{lr}\text { Chi } & \text { Square } \\
\text { Fisher } & \text { Exact } \\
\text { Test } \chi^{2} & \\
\end{array}$ & P-Value* \\
\hline Hypotension & $23(19)(0.84)$ & $15(19)(0.84)$ & 38 & \multirow{3}{*}{5.933} & \multirow{3}{*}{$0.0321 *$} \\
\hline Normotension & $7(11)(1.45)$ & $15(11)(1.45)$ & 22 & & \\
\hline Total No. & 30 & 30 & 60 & & \\
\hline
\end{tabular}

*The result is significant at $\mathrm{P}<0.10$

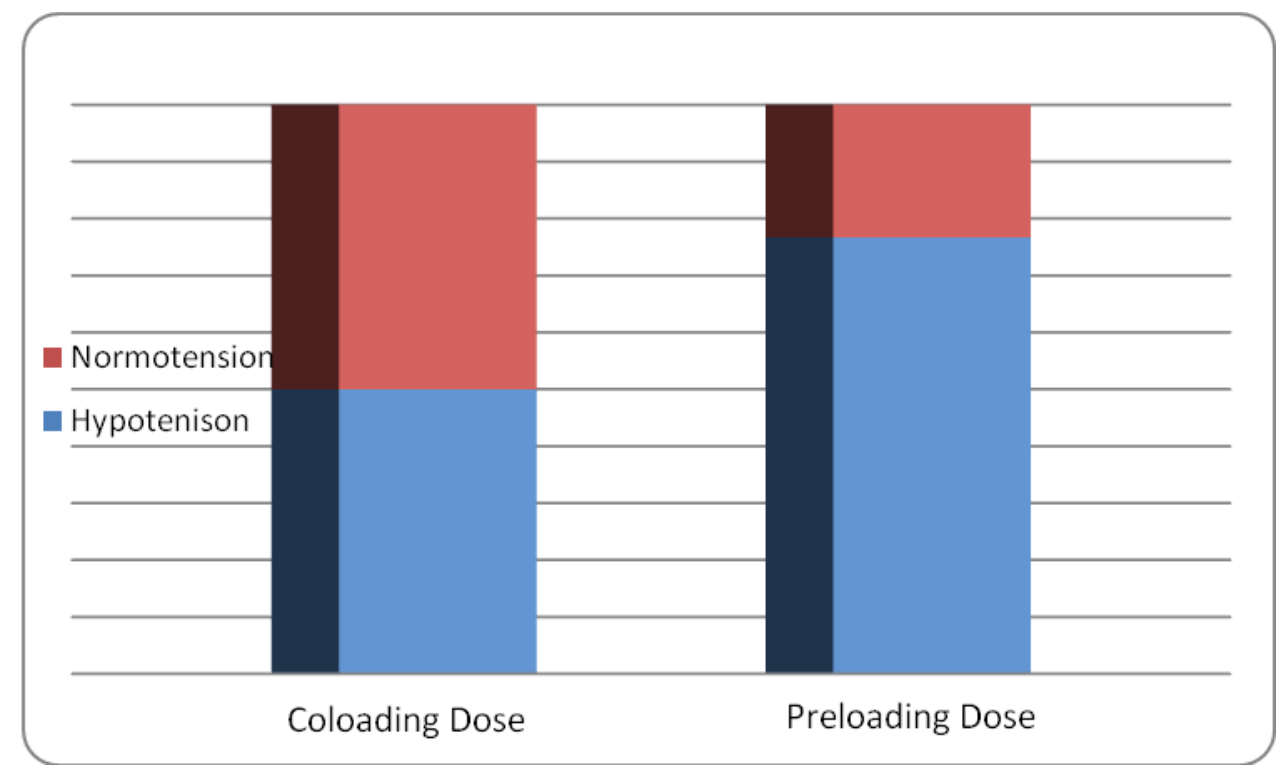

Figure 1:- Distribution of hypotension occurrence according to Preloading/Coloading Dose.

\section{Discussion:-}

Both general and spinal anaesthesia have certain advantages and disadvantages, but regional anaesthesia has become the preferred technique, Because general anaesthesia has been associated with Higher maternal mortality and fetal depression, neural blockade or local anesthetic toxicity"[1].

In our study 60 patients were selected from age ranging (18-37) years, all patients we are selected within American Society of Anesthesiologists Classification(ASA) class1then divided into two groups 30 patients weremanaged with coloading fluids and blood pressure was measured for all patients before and after induction of spinal anaesthesia and the results were compared between the two groups. It were detected that there was significant difference between management of hypotension due to spinal anaesthesia by giving the patient co-loading or preloading crystalloid fluids, these were in accordance to the findings reported by other study[5].

\section{Conclusions:-}

There is significant difference between the effect of preloading and coloading on blood pressure after spinal anesthesia.

\section{Recommendations:-}

1-Choose the method which is safest and most comfortable for mother to control hypotension.

2-Try to study other study trends to confirm this results.

3-Keep in your mind that hypotension can be managed with vasoconstructer medications in addition to fluids. 


\section{References:-}

1. Rout C, Rocke DA. Spinal hypotension associated with Cesarean section: will preload ever work? Anesthesiology 1999; 91:1565-72.

2. Jackson R, Reid JA, Thorburn J. Volume preloading is not essential to prevent spinal-induced hypotension at Caesarean section. Br J Anaesth 1995;75:262-5.

3. Husaini SW, Russell IF. Volume preload: lack of effect in the prevention of spinal-induced hypotension at caesarean section. Int J ObstetAnesth 1998;7:76-81.

4. NganKee WD. Prevention of maternal hypotension after regional anaesthesia for caesarean section. CurrOpinAnaesthesiol. 2010;23:304-9. [PubMed].

5. Dyer RA, Farina Z, Joubert IA, Du Toit P, Meyer M, Torr G, Wells K, James MF. Crystalloid preload versus rapid crystalloid administration after induction of spinal anaesthesia (coload) for elective caesarean section. Anaesth Intensive Care 2004;32:351-7.

6. Ueyama H, He YL, Tanigami H, Mashimo T, Yoshiya I. Effects of crystalloid and colloid preload on blood volume in the parturient undergoing spinal anesthesia for elective Cesarean section. Anesthesiology 1999;91:1571-6.

7. Robson S, Hunter S, Boys R, Dunlop W, Bryson M. Changes in cardiac output during epidural anaesthesia for caesarean section. Anaesthesia 1989;44:475-9.

8. Robson SC, Boys RJ, Rodeck C, Morgan B. Maternal and fetal haemodynamic effects of spinal and extradural anaesthesia for elective caesarean section. Br J Anaesth 1992;68:54-9.

9. Skjoldebrand A, Eklund J, Johansson H, Lunell NO, Nylund L, Sarby B, Thornstrom S. Uteroplacental blood flow measured by placental scintigraphy during epidural anaesthesia for caesarean section. ActaAnaesthesiolScand 1990;34:79-84. 